\title{
Espaços e caminhos da educação alimentar \\ e nutricional no livro didático
}

\section{Dialogue concerning the limits and possibilities of food and nutrition education through school textbooks}

\author{
Suzana de Azevedo Greenwood ${ }^{1}$. Alexandre Brasil Fonseca ${ }^{1}$
}

\begin{abstract}
Resumo: Este estudo descreve como se constitui a educação alimentar e nutricional (EAN) presente no livro didático (LD) da Educação Básica, visualizando espaços e caminhos que possibilitam a otimização desta. Seguiu-se uma metodologia guiada pela Hermenêutica de Profundidade. Inicialmente, se situa a EAN posicionada no tempo e espaço dentro do contexto do Programa Nacional do Livro Didático (PNLD). Exploram-se os campos de interação que agem na configuração da EAN no LD. Os resultados apontam fatores no âmbito governamental, campo editorial e contexto escolar que formatam a EAN e são relevantes neste processo. Em conclusão, sugere-se: que os alimentos apresentados no LD devam refletir a diversidade contextual brasileira, que autores e professores estejam envolvidos nos círculos de discussão sobre a temática, e que o LD fomente o diálogo centrado na EAN, abordando os objetivos e as práticas de programas governamentais afins, como merendas e hortas, presentes na escola.
\end{abstract}

Palavras-chave: Educação alimentar e nutricional. Livro didático. Educação Básica. Programa Nacional do Livro Didático (PNLD).

\begin{abstract}
This study describes how Food and Nutrition Education (FNE) is presented in Brazilian secondary School Textbooks and seeks to identify spaces and directions which can optimize FNE. The Depth Hermeneutics methodology is followed. Firstly, the time and space frame for FNE is identified, within the context of the National School Textbook Programme (PNLD), The fields of interaction which influence the formulation of FNE in textbooks are explored. Results indicate factors in governmental and editorial spheres, and in the school context, which shape FNE and are relevant in the educative process. In conclusion, it is suggested that foods presented in textbooks should reflect the diversity present the differing Brazilian contexts; that authors and teachers be involved in discussion circles related to the theme; and that textbooks should stimulate FNE focussed dialogue, including in discussion the objectives and practices of related government programmes present in schools, such as school lunches and vegetable gardens.
\end{abstract}

Keywords: Food and nutrition education. School textbook. Basic education. Brazilian National School Textbook Programme.

\footnotetext{
${ }^{1}$ Universidade Federal do Rio de Janeiro (UFRJ), Núcleo de Tecnologia Educacional para a Saúde (Nutes), Rio de Janeiro, RJ, Brasil. E-mail: <azewood@outlook.com>
} 
A Educação Alimentar e Nutricional (EAN) tem se figurado como elemento importante na promoção à saúde, tanto no âmbito nacional quanto no internacional. Em sua trajetória, tem havido modificações, partindo de um patamar onde estratégias de EAN eram desenvolvidas com o objetivo de ensinar a alimentação considerada correta, de maneira descontextualizada e com um olhar estritamente biológico. Gozando de maior presença em documentos públicos, as ações de EAN, atualmente, buscam englobar a multiplicidade de fatores e nuances imbricadas no ato de alimentar-se e de fazer escolhas, incluindo os conceitos do Direito Humano a Alimentação Adequada e da Segurança Alimentar e Nutricional

Estas mudanças têm sido refletidas na nomenclatura desta educação. Casemiro (2013), em levantamento de artigos sobre este tema publicados no Brasil entre 1974 e 2011, identifica que o termo Educação Nutricional esteve presente durante todo o período; Educação Alimentar e Nutricional, por sua vez, começa a ser utilizado a partir de 1999. Entende-se que a educação nutricional oferece uma conotação técnica e de adequação às necessidades biológicas, enquanto, ao falar-se em educação alimentar, busca-se o contexto do consumo com um olhar para a cultura, costumes e cotidiano. Unindo os dois termos, a Educação Alimentar e Nutricional engloba estas duas facetas e denota uma ação mais completa, condizente com os seus objetivos. Este processo de mudança reflete a percepção de que uma abordagem educacional restrita, com foco simplesmente biomédico, não alcança os objetivos desta ação.

No cenário brasileiro, o interesse pela Educação Nutricional (EN) brotou na década de 1940, época em que era vista como uma coluna em programas governamentais de proteção ao trabalhador (BOOG, 1997). Até a década de 1970, a EN vivenciou momentos de rejeição em diversos contextos, devido às concepções que norteavam as ações naquele período com conotações discriminatórias e redução ao biológico. A partir daí, o tema pouco evoluiu por duas décadas até ser retomado nos anos de 1990 com as evidências de que hábitos alimentares são determinantes para a saúde (BRASIL, 2012).

Demarcando estes ventos de mudanças, BOOG (1997), nos anos finais da década de 1990, sugere alternativas para alterar a trajetória da educação nutricional. Pautando-se em Paulo Freire, esta autora argumenta sobre a importância do engajamento com a realidade e do diálogo entre as pessoas no processo educativo. Não ficou alheia, às reflexões desta autora, a compreensão de que dimensões culturais e psicológicas são inerentes aos processos que envolvem a alimentação do indivíduo.

Prosseguindo nesta direção, o desenvolvimento de discussões e conceitos sobre EAN tem se aprofundado e ampliado o seu espaço. A EAN tem sido objetivo compartilhado por diferentes ministérios na esfera governamental: o Ministério da Saúde tem publicado o Guia Alimentar para a População Brasileira; o Ministério da Educação (MEC) traz Saúde como tema transversal nos parâmetros curriculares nacionais (PCN), e, em 2012, o Ministério do Desenvolvimento Social e Combate à Fome (MDS) lança o Marco de Referência de Educação Alimentar e Nutricional para as Politicas Públicas (BRASIL, 2012), que desponta com o objetivo de coordenar ações de EAN e promover espaço tanto para reflexão quanto de orientação desta prática às iniciativas originadas, sobretudo, na ação pública. O Marco, documento acima citado, surgiu devido à necessidade de se ampliar a discussão sobre as possibilidades, limites e o modo como é a EAN é realizada. Todavia, mesmo diante de avanços e acúmulos de conhecimento sobre EAN, seu campo de atuação não está claramente definido, havendo entendimentos diversos quanto a sua abordagem conceitual e prática. 
Espaços e caminhos da educação alimentar e nutricional ...

Ademais, há falta de robustez nos processos de planejamento da EAN e parca presença desta nos programas públicos (BRASIL, 2012). Ou seja, existe a necessidade de espaço e diálogo para que conceitos em EAN sejam formulados e solidificados para um fortalecimento e implementação de seus processos nas esferas públicas.

Amparo-Santos (2013), discorrendo sobre possíveis desdobramentos decorrentes da publicação deste Marco, reforça a importância de fatores socioculturais, simbólicos, afetivos e sensoriais da alimentação no processo educativo desta temática, e argumenta que o diálogo se traduz no principal instrumento da EAN, sendo o diálogo de saberes a maior provocação que o referido documento oferece.

Fortalecendo as vozes que apontam fatores sociais como imprescindíveis na EAN, o Ministério da Saúde lança, em 2014, uma nova versão do Guia Alimentar para a População Brasileira. Neste documento, os "Dez Passos Para uma Alimentação Saudável” dão maior visibilidade a aspectos sociais e menos ao caráter prescritivo de orientação nutricional. Este Guia busca propiciar diálogo entre profissionais e a população, e é um instrumento estratégico de EAN para o SUS e outros setores (BRASIL, 2014b).

Desta forma, espaços têm sido criados para que conceitos em EAN sejam formulados, testados e dialogados. Isto tem favorecido a formação de um traçado orientador às ações deste campo sem, todavia, impedir a ampliação e aprofundamento dos saberes que orientam esta prática.

O contexto escolar tem sido entendido como valioso para o desenvolvimento da EAN, dado que os alunos ali inseridos estão não somente em processo de crescimento físico, mas de formulações de seus conceitos e valores.

Bizzo e Leder (2005) defendem que a EAN seja explícita nos PCN. Mesmo que isto não ocorra nestes termos, Saúde como tema transversal nos PCN tem propiciado que conteúdo de EAN encontre seu lugar no currículo escolar por meio do livro didático (PIPITONE et al., 2003).

O Programa Nacional de Livro Didático (PNLD) oferece livro didático (LD) de ciências a todo estudante da rede pública da Educação Básica. Por suas características, a disciplina de ciências oferece fartas oportunidades de conexão entre EAN e os outros conteúdos alocados a esta disciplina. Pela ampla capilarização de seu alcance, o LD é uma ferramenta valorosa para a EAN. Pesquisas têm mostrado que os professores da Educação Básica não seguem fielmente os LDs na forma como concebidos e disseminados por autores e editoras (MEGID NETO; FRACALANZA, 2003). No entanto, este continua sendo importante objeto de consulta e apoio para o planejamento do professor, e, por vezes, a única fonte de leitura para informação e conhecimento disponível ao estudante e sua família (ROSA, 2013).

O potencial, inerente ao LD, de favorecer ações educativas em alimentação e nutrição levanta algumas questões: como a EAN tem sido apresentada no LD? Quais as abordagens adotadas? Têm os atores sociais que formatam a EAN no LD participado das recentes discussões de formulação de conceitos e descobrimentos de caminhos para a EAN ocorridas no Brasil? Como a EAN no LD tem sido utilizada?

Portanto, tendo em vista o valor da EAN na promoção da saúde, a ampla presença do LD nas escolas e a posição privilegiada que o LD goza para balizar práticas pedagógicas dentro do contexto escolar, este estudo busca: descrever de que forma a EAN presente no LD da Educação Básica é formatada, analisar os fatores que influenciam sua utilização, e visualizar espaços e caminhos que potencializam a EAN desenvolvida a partir do LD. 


\section{Caminho metodológico}

Este estudo foi guiado por duas etapas da Hermenêutica de Profundidade, conforme descrito por Thompson (1995), a saber: a análise espaço temporal e os campos de interação. Thompson (1995) lembra-nos que formas simbólicas, neste caso, o livro didático, são produzidas e recebidas por pessoas situadas em locais particulares, reagindo a tempos específicos. A reconstrução destes ambientes é a análise espaço-temporal. Nos campos de interação, indivíduos baseiam-se em diferentes tipos de recursos, assim como em regras e convenções diversas, explícitas ou não, para alcançar os seus objetivos e interesses particulares.

A coleta de dados deu-se por meio de: pesquisa em documentos governamentais, entrevistas com atores de produção e recepção do LD, e análise de textos de LD.

Dado que o LD é produzido, sobretudo, na região Sudeste, buscou-se um olhar de atores sociais de recepção fora desta região. Assim, para escolha dos entrevistados, foi enviada correspondência, explicando os objetivos da pesquisa, às Secretarias de Educação dos seis municípios, fora da região Sudeste, vencedores do Prêmio Gestor Eficiente de Merenda Escolar 2012, promovido pela ONG Ação Fome Zero (http:/ / acaofomezero.org.br), na categoria "Eficiência e Educação Alimentar e Nutricional".

Aos três municípios que responderam, foi solicitado que indicassem duas escolas de Ensino Fundamental II (EFII) onde a pesquisa pudesse ser realizada e dois professores de ciências do oitavo ano de cada escola a serem entrevistados. O livro de ciências utilizado em cada contexto foi analisado e seus autores entrevistados.

O oitavo ano do EFII foi escolhido pois, tradicionalmente, no seu conteúdo programático, são estudados os sistemas do corpo humano, incluindo o sistema digestório, configurando, assim, maiores possibilidades de se encontrarem abordagens de EAN no LD, e de que estas estivessem sendo desenvolvidas pelo professor.

As entrevistas com atores de recepção, os professores, ocorreram nas regiões Centro-Oeste, Nordeste e Sul. Os professores entrevistados foram identificados de acordo com a região: CO-Prof 1, CO-Prof 2; NE-Prof 1, NE-Prof 2; S-Prof 1, S-Prof 2. Os autores e livros foram identificados como: Autor 1 (livro utilizado na região CO), Autor 2 (livro utilizado na região NE) e Autor 3 (livro utilizado na região S). Os livros foram denominados: Livro 1, Livro 2 e Livro 3, respectivamente. Ademais, dois avaliadores das coleções de ciências do PNLD 2014 foram entrevistados.

Esta pesquisa foi submetida e aprovada pelo Comitê de Ética em Pesquisa do Instituto de Estudos em Saúde Coletiva da Universidade Federal do Rio de Janeiro.

\section{A educação alimentar e nutricional e o livro didático posicionados no espaço e no tempo}

O Quadro 1 reconstrói as situações espaço-temporais de produção, circulação e recepção do livro didático de ciências do PNLD 2014 (BRASIL, 2014a), tendo um olhar direcionado não somente às coleções como um todo, mas ao conteúdo de EAN presente no LD. Busca-se, com este exercício, visualizar espaços que, potencialmente, moldam a EAN no LD, e, posteriormente, a partir destes espaços, discutir caminhos que favoreçam a otimização da EAN no LD. Essa tabela mostra que caminho da EAN passa pela esfera governamental, pelas editoras e pelo contexto escolar. 
Quadro 1. Situações espaço-temporais da produção e recepção do livro didático do PNLD 2014

\begin{tabular}{|c|c|c|c|c|}
\hline TEMPO & $\stackrel{\text { ESPAÇO }}{\longrightarrow}$ & GOVERNO & EDITORAS & ESCOLAS \\
\hline \multirow{5}{*}{ 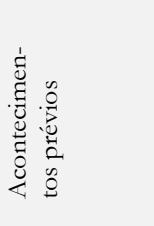 } & \multirow{5}{*}{$\frac{\mathscr{n}}{I}$} & 1985 - MEC - PNLD & \multirow{5}{*}{$\begin{array}{l}\text { Editora convida e contrata } \\
\text { autores para escrita do livro, } \\
\text { ou produtora de livros para } \\
\text { escrita do texto } \\
\text { Escrita e editoração do livro }\end{array}$} & \\
\hline & & $\begin{array}{l}1988 \text { - Constituição da República } \\
\text { Federativa do Brasil }\end{array}$ & & \\
\hline & & 1990 - MS - Lei 8080 & & \\
\hline & & 1996 - MEC - LDB & & \\
\hline & & 1997 - MEC - PCN & & \\
\hline Ano $1 / 2011$ & Nov & $\begin{array}{l}\text { 07/11/11 - Publica Edital PNLD } \\
2014 \text { para editoras }\end{array}$ & $\begin{array}{l}\text { 09/12/2011 - Início inscri- } \\
\text { ção das coleções no PNLD }\end{array}$ & \\
\hline \multirow[t]{2}{*}{ Ano 2/2012 } & Jan/ Maio & $\begin{array}{l}\text { Recebimento das inscrições das } \\
\text { editoras }\end{array}$ & $\begin{array}{l}\text { 01/05/2012 - Término } \\
\text { inscrição das coleções no } \\
\text { PNLD: }\end{array}$ & \\
\hline & Out/Dez & \multirow{2}{*}{$\begin{array}{l}\text { Triagem/Avalição das coleções } \\
\text { 1. Física - IP'T } \\
\text { 2. Pedagógica - SEB/MEC } \\
\text { (UFSCar) }\end{array}$} & & \\
\hline \multirow[t]{9}{*}{ Ano 3/2013 } & Jan & & & \\
\hline & Fev/ Abril & $\begin{array}{l}\text { Avaliação das coleções pela equipe } \\
\text { técnica FNDE }\end{array}$ & & \\
\hline & Maio & $\begin{array}{l}08 \text { de maio - resultado da avaliação } \\
\text { das coleções } \\
13 \text { de maio - apresentação de recur- } \\
\text { sos pelas editoras }\end{array}$ & $\begin{array}{l}08 \text { de maio - editoras rece- } \\
\text { bem resultado da avaliação } \\
\text { do FNDE } \\
13 \text { de maio - apresentação } \\
\text { de recursos ao FNDE }\end{array}$ & $\begin{array}{l}\text { Até maio de } 2013 \text {, } \\
\text { escolas aderem ao } \\
\text { PNLD online } \\
\text { Só é necessário que isto } \\
\text { seja feito uma vez por } \\
\text { escola }\end{array}$ \\
\hline & Jun/ Jul & $\begin{array}{l}\text { Disponibilização do Guia PNLD } \\
2014 \text { pela internet e cópia impressa } \\
\text { enviada às escolas cadastradas }\end{array}$ & $\begin{array}{l}\text { Editoras enviam suas cole- } \\
\text { ções para as escolas }\end{array}$ & $\begin{array}{l}\text { Acesso ao Guia PNLD } \\
2014 \\
\text { Recebimento de cole- } \\
\text { ções das editoras por } \\
\text { correio para avaliação }\end{array}$ \\
\hline & Agosto & $\begin{array}{l}\text { Recebimentos online das escolhas de } \\
\text { coleções pelas escolas }\end{array}$ & \multirow[t]{2}{*}{$\begin{array}{l}\text { Editoras que tiveram livros } \\
\text { escolhidos negociam com } \\
\text { o MEC }\end{array}$} & $\begin{array}{l}\text { 02-12 agosto - escolas } \\
\text { escolhem } 2 \text { coleções } \\
\text { (opção } 1 \text { e } 2 \text { ) de editoras } \\
\text { diferentes e enviam ao } \\
\text { governo }\end{array}$ \\
\hline & Setembro & $\begin{array}{l}\text { Negociação com as editoras e } \\
\text { compra dos LDs }\end{array}$ & & \\
\hline & Out & \multirow{2}{*}{$\begin{array}{l}\text { Supervisão da produção dos livros } \\
\text { por FNDE e IPT }\end{array}$} & \multirow[t]{2}{*}{ Produção dos livros } & \\
\hline & Nov & & & \\
\hline & Dez & \multirow{2}{*}{$\begin{array}{l}\text { FNDE contrata Correios para en- } \\
\text { tregar livros da editora diretamente } \\
\text { para escolas }\end{array}$} & \multirow{2}{*}{$\begin{array}{l}\text { Entrega dos livros ao } \\
\text { correio }\end{array}$} & \\
\hline Ano 4/2014 & Jan-Fev & & & $\begin{array}{l}\text { Recebimento dos livros } \\
\text { escolhidos nas escolas }\end{array}$ \\
\hline & Fev -Dez & $\begin{array}{l}\text { Edital para PNLD } 2017 \text { - anos } \\
\text { fundamentais }\end{array}$ & & \multirow{3}{*}{$\begin{array}{l}2014 \text { a } 2016 \\
\text { Utilização do LD pelo } \\
\text { professor e aluno }\end{array}$} \\
\hline Ano 5/2015 & Jan-Dez & Inscrição PNLD 2017 & Inscrição PNLD 2017 & \\
\hline Ano 6/2016 & Jan-Dez & $\begin{array}{l}\text { Avaliação e resultado } \\
\text { PNLD } 2017\end{array}$ & $\begin{array}{l}\text { Avaliação e resultado } \\
\text { PNLD } 2017\end{array}$ & \\
\hline
\end{tabular}

Fonte: elaborado pelos autores. 
O governo traça diretrizes e leis que, ao direcionarem os processos de produção do livro didático, direta ou indiretamente, balizam o conteúdo de EAN presente no LD.

No campo da educação, o PNLD, programa do FNDE, autarquia responsável pela execução das políticas educacionais do Ministério da Educação (MEC), provê escolas públicas com livros didáticos, segundo estabelecido na Constituição Brasileira (BRASIL, 1988) e explicitado na Lei das Diretrizes e Bases da Educação Nacional (LDB) (BRASIL, 1996) e no Estatuto da Criança e do Adolescente (BRASIL, 1990a). No campo da saúde, a Lei 8080, de 1990, dispõe sobre a promoção da saúde, campo no qual se insere a EAN. No artigo 2, Alínea 1, lê-se: "O dever do Estado de garantir a saúde consiste na formulação e execução de políticas econômicas e sociais que visem [...] a sua promoção, proteção e recuperação" (BRASIL, 1990b). Em 1997, os PCN inseriram Saúde como tema transversal a ser desenvolvido com estudantes de Ensino Fundamental (BRASIL, 1997). Os três livros didáticos analisados oferecem conteúdo de EAN que refletem esses direcionamentos, todavia, interessa-nos a forma como esta é abordada, análise que faremos mais adiante.

A cada triênio, o PNLD publica edital com direcionamentos em relação ao livro didático do EFII, com orientações sobre os princípios e critérios de avaliação para que uma coleção seja aprovada pelo FNDE e inclusa no Guia PNLD. Somente as coleções inseridas neste Guia são compradas pelo MEC. As editoras interessadas observam atentamente este edital, preparam suas coleções e as inscrevem no programa.

Para o componente curricular de Ciências, o edital de PNLD 2014 orienta que a coleção contribua para familiarizar o estudante com os procedimentos característicos da investigação científica, não focando no mero repasse de informações e memorização. Indo além, é esperado que, ao oferecer o conteúdo desta disciplina, o LD valorize temas e práticas próximas da realidade dos alunos, articulando os conteúdos de Ciências com outros campos e propondo atividades que estimulem a interação e participação da comunidade escolar, das famílias e da população em geral. Ademais, esse documento orienta que a coleção sugira atividades lúdicas e proponha visitas a espaços úteis ao processo de ensino-aprendizagem, como museus e fábricas (BRASIL, 2011).

A avaliação pedagógica das coleções de ciências inscritas pelas editoras no PNLD 2014 é feita por especialistas da área do Ensino de Ciências, sobretudo, profissionais que atuam em universidades. Para o PNLD 2014, pelo menos 11 dos 32 avaliadores destas coleções são biólogos (não foi possível acessar a informação de dois dos avaliadores), seguidos de físicos, químicos, entre outros. Mesmo não sendo fator determinante, a formação do biólogo amplia a possibilidade de olhar acurado para a EAN.

Os avaliadores entrevistados discutem esta questão:

O biólogo vai ter um olhar mais acurado para a sua área, o químico para a sua, e assim por diante. O ideal é que o livro passasse por um crivo de avaliadores de todas as áreas, mas isto seria muito caro e inviável. [Avaliador 1 - Biólogo]

Eu estou mais envolvido nas ciências mais duras, principalmente física, pela minha prática profissional. As coisas que eu detectei mais erros e mais falbas foi mais na física, quase nunca na biologia. [Avaliador 2 - Bioquímico] 
Espaços e caminhos da educação alimentar e nutricional ...

Como avaliador do PNLD, este profissional não pode trazer sugestões, mas preenche a "Ficha para avaliação da Obra", composta de 25 perguntas que avaliam os diversos aspectos da coleção, as quais devem ser respondidas com "Não" ou "Sim". A resposta negativa a qualquer item exclui a obra e deve ser justificada. Itens marcados com respostas "Sim" são graduados com notas de 1 a 4, acompanhadas de argumentos consistentes e de exemplos relevantes identificados nos livros (BRASIL, 2013).

Quando a etapa de avaliação é encerrada, resenhas das coleções aprovadas são publicadas no Guia PNLD disponibilizado na internet e enviado às escolas. O Guia PNLD 2014 alerta professores que o foco na escolha de um bom livro está em observar a proposta pedagógica. Esta deve oferecer ensino investigativo e experimental e, para a coleção de Ciências, deve assegurar aspectos centrais da saúde (BRASIL, 2013).

Do ponto de vista das editoras, o processo inicia-se bem antes da liberação do edital do PNLD do ano em questão. Tendo em vista a venda de seus produtos ao MEC, seu maior comprador, as editoras buscam autores que possam produzir livros que venham refletir as tendências das orientações dos PNLDs anteriores.

É interessante notar que todas as editoras presentes no Guia PNLD 2014, com exceção de uma, estão sediadas em São Paulo, e 70\% das coleções presentes neste Guia pertencem a apenas quatro grupos editoriais. Além disso, 66,7\% das compras do PNLD 2014 foram de coleções destas quatro editoras. Estes dados revelam a maneira como o mercado do livro didático está configurado neste momento, concentrado sob a influência de um número pequeno de editoras e autores presentes majoritariamente na região Sudeste (FUNDO NACIONAL DE DESENVOLVIMENTO DA EDUCAÇÃO, 2014).

Seguindo o quadro 1, a participação da escola, neste processo, inicia-se com sua adesão ao PNLD online. Semanas antes da data da escolha do LD, as escolas recebem coleções de livros das diferentes editoras. Os professores passam, então, a analisar as coleções e decidir qual escolher. É objetivo do FNDE que esta escolha se dê por meio de mecanismos que buscam assegurar a autonomia do professor (BRASIL, 2013). Terminado este processo, as coleções são enviadas às escolas antes do início letivo, quando estes livros são então utilizados.

Acrescenta-se, ao cenário acima descrito, o fato de que a produção acadêmica referente a EAN tem sido um espaço de influência nas esferas governamental, editorial e escolar.

\section{Campos de interação que influenciam a educação alimentar e nutricional presente no livro didático}

Tendo descrito como a EAN presente no LD situa-se no tempo e no espaço, busca-se, aqui, discutir os fatores que influenciam a sua formatação durante o processo de produção e utilização desta forma simbólica, tendo como pano de fundo o entendimento dos campos de interação, como descritos por Thompson (1995).

\section{O processo de avaliação do PNLD e a EAN no LD}

Retomando as orientações do PNLD, que encorajam a valorização da realidade do aluno no processo educativo, percebe-se que estas orientações corroboram com outras diretrizes governamentais, ou seja, os PCN e o próprio Marco trazem este olhar freireano nos direcio- 
namentos dos processos educativos. Entendemos que estas semelhanças podem ser fruto do alcance da produção acadêmica no campo educacional e de influências mútuas nas diferentes políticas públicas.

Ademais, percebemos que, nestas diretrizes, encontra-se arcabouço favorável ao desenvolvimento da EAN permeada por diálogos entre os alunos e, mesmo, trocas com atores sociais fora do contexto escolar, além da possibilidade de vivenciar experiências com alimentos durante este processo educativo, como, por exemplo, atividades na horta escolar. Estas orientações possibilitam, também, trazer à discussão questões sobre Direito Humano à Alimentação Adequada e a garantia da Segurança Alimentar e Nutricional, questões estas que permeiam a promoção da prática autônoma e voluntária de hábitos alimentares saudáveis.

Todavia, o simples fato de que as orientações do PNLD viabilizam uma abordagem abrangente de EAN não, necessariamente, resulta em concretização desta possibilidade nas páginas do LD. Com foco no processo avaliativo das coleções, visualiza-se, na "Ficha para avaliação da Obra", uma possibilidade de comunicação com o campo editorial quanto à abordagem preconizada para a EAN e uma oportunidade de fomento deste olhar amplo e atual da EAN. A fala de um dos avaliadores entrevistados, um biólogo, revela a contribuição que estes poderiam trazer à autoria do LD:

Esta estratégia de fazer tabelinha com os nutrientes e as vantagens e carências, isto não funciona com adolescente, e nem com adulto. É mais interessante que se tenha um certo tipo de convivio problematizador com aquelas questões: porque que tem pouco sal? A comida está ruim? Houve reclamação na escola? Então vamos conversar porque a comida está ruim. Vamos chamar o pessoal da cožnha, são elas que entendem, tem este saber, são preparadas para isto. Ou então: as crianças não estão comendo porque tem um matinho, cheiro verde? Então vamos plantar! Vamos mostrar às crianças a vitamina presente na salsa, vamos criar um vinculo afetivo com a planta, porque quando se planta, mesmo que seja um vasinho na janela, você cria um vinculo afetivo com a planta, e facilita a aceitação. [Avaliador 1]

No espaço dado ao avaliador, na "Ficha para avaliação da Obra", para justificar uma resposta negativa, ou argumentar a nota dada a uma resposta positiva, conceitos como os denotados na fala acima poderiam ser inseridos. Contudo, para que esta comunicação ocorra de forma a beneficiar a EAN, é necessário que o avaliador tenha conhecimento e interesse em fomentar o tema. Para tanto, idealmente, este avaliador poderia estar envolvido nos círculos de discussão da EAN, o que recai no âmbito da "coincidência", visto que este não é um critério de seleção para ser um avaliador do FNDE.

O fomento das discussões e a ampliação de ambientes onde estes diálogos ocorrem, incluindo as universidades, local onde, tradicionalmente, estão inseridos os avaliadores, propiciam maiores chances de que esta voz chegue até o campo editorial. Vale reforçar aqui que as editoras dão grande importância a estas fichas avaliativas, pois todas buscam ter suas coleções aprovadas pelo PNLD.

A configuração do campo editorial no PNLD, com um grupo pequeno de editoras no Sudeste dominando este mercado, leva-nos a refletir sobre o conceito de "violência simbólica", como descrito por Bourdieu (BOURDIEU; PASSERON, 1975). Este sociólogo argumenta que 
toda ação pedagógica é objetivamente uma violência simbólica, pois impõe um poder arbitrário ao apresentar a cultura dominante como cultura geral. O LD como ferramenta pedagógica é, também, ferramenta deste poder arbitrário, dado que seu conteúdo é resultante de diretrizes e decisões de membros da cultura dominante.

Não obstante, no conteúdo de EAN presente no LD, mesmo considerando a realidade acima levantada, podem-se enxergar dois atenuantes a esta situação: primeiramente, o Novo Guia Alimentar, e o Marco, citados anteriormente, têm sido elaborados a partir de discussões presenciais e virtuais envolvendo profissionais da área, pesquisadores e sociedade civil. Assim, mesmo idealizados e finalizados por instâncias governamentais, estes documentos trazem, em seu corpo, a possibilidade de que vozes da sociedade civil estejam representadas.

Assim sendo, quando a EAN apresentada no LD sintoniza com as orientações dos documentos acima citados, há maior chance de que EAN toque na realidade de professores e alunos ao redor do Brasil do que se esta for, simplesmente, uma reprodução do que já tem sido feito no campo editorial. Em segundo lugar, espelhando as orientações destes documentos governamentais, a EAN tem, no diálogo, seu mais importante instrumento. Assim, como nos ensina Paulo Freire, a realidade mediatizadora de cada local encontra espaço para configurar esta ação pedagógica (FREIRE, 1996).

A realidade mediatizadora na temática em questão é o alimento. Não qualquer alimento, mas os que são acessíveis à população onde a ação educacional é desenvolvida. Este entendimento de acessibilidade abarca tanto o ponto de vista econômico quanto o geográfico, sem ignorar as barreiras culturais, por vezes, atribuídas a determinados alimentos. A maneira como se prepara a comida, o momento do dia em que se come e o status atribuído a cada alimento são valores intimamente ligados à cultura local. Por sua vez, merenda escolar, regimentada pelo PNAE, é presença tão universal nas escolas públicas quanto o LD, e, portanto, pode ser um trunfo na mediação deste processo educacional.

Torna-se essencial que se ponderem estas nuances no desenvolvimento do processo pedagógico em alimentação e nutrição. Assim, considerando que a EAN oferecida no LD é escrita por um grupo no Sudeste e desenvolvida em todas as escolas públicas do território nacional, sua abordagem é beneficiada quando encoraja amplas oportunidades de diálogo em cada realidade local.

\section{O autor e a escrita do livro didático}

Dentro do campo editorial, está o autor, que é a figura central na escrita do LD e que toma decisões, neste processo, baseado e influenciado por fatores diversos, como exemplificado na Figura 1.

Dentre os livros de ciências do EFII adquiridos no PNLD 2014, mais de 50\% provêm de quatro coleções, escritas por cinco pessoas (quatro autores, e um editor que assina uma das coleções). Isso significa que 6.726.186 livros de ciências do Ensino Fundamental II foram adquiridos pelo Ministério da Educação (MEC) para serem utilizados durante três anos, e tão somente cinco pessoas assinam a autoria (FUNDO NACIONAL DE DESENVOLVIMENTO DA EDUCAÇÃO, 2014). Ou seja, potencialmente o texto escrito por estes cinco autores é lido por mais de 20 milhões de alunos, além de seus professores e familiares. 
Figura 1. Campos de interação na escrita do LD, sob o prisma da EAN

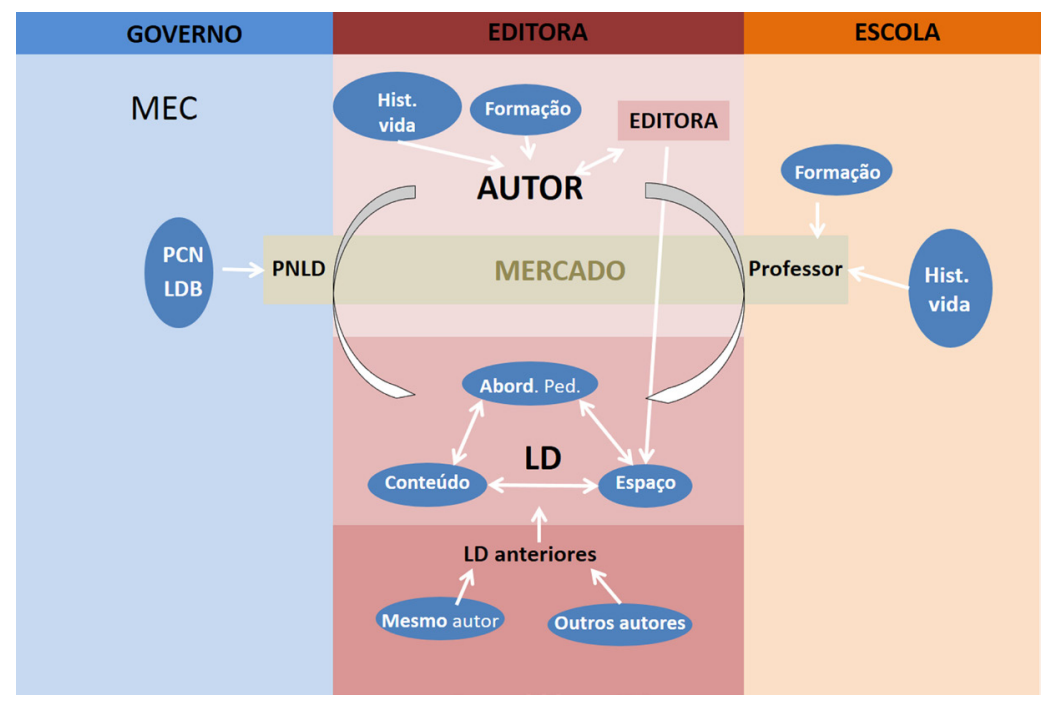

Fonte: elaborada pelos autores.

O processo de escrita de um livro didático não se dá de maneira individual, todavia, não se pode negar a grande parcela de decisões alocadas pelo autor. Assim sendo, é válido analisar os fatores que influenciam as decisões do autor, tendo por objetivo identificar os que levam o autor a tomar decisões favoráveis a EAN no LD, tanto em relação à presença deste tema, quanto a sua abordagem. Durante as entrevistas com os autores, ficou evidente que a história de vida e formação do autor matizam suas escolhas.

Considerando o PNLD 2014, três dos cinco autores que escreveram mais de 50\% das coleções de ciências adquiridas, são biólogos. A formação em biologia, mesmo que não determinante, é fator favorável à inclusão da EAN no LD, se comparado a matemáticos, físicos e químicos, profissionais que, tradicionalmente, dedicam-se à autoria dos livros de ciências.

A afinidade pessoal do autor com o tema pode influenciar, de maneira significativa, a maneira como este é apresentado no LD. O interesse por EAN é delineado pela formação e história de vida do autor. Durante entrevista, o Autor 1 expressou o valor que confere ao tema da alimentação saudável e sua preocupação tanto com a questão da obesidade na adolescência, quanto com o perigo das práticas não fundamentadas em conhecimento científico, na busca do "corpo ideal". O livro de ciências de oitavo ano de sua autoria aborda o tema alimentação em 33 páginas, destinando mais 14 páginas para o sistema digestório. Em três capítulos, este autor dedica duas páginas e meia ao tema obesidade. Em contraste, o Autor 3 aborda o sistema digestório e alimentação conjuntamente em um único capítulo com 23 páginas, no qual encontram-se, apenas, breves menções em relação a sobrepeso e obesidade. O Livro 2, por sua vez, apresenta 37 páginas sobre o tema em dois capítulos.

Considerando a importância da questão cultural na EAN, é interessante notar que, durante as entrevistas, somente um dos autores abordou espontaneamente a questão cultural: 
Espaços e caminhos da educação alimentar e nutricional ...

A questão da alimentação é bastante cultural, e o local melhor para trabalhar esta questão de cultura é na escola, primeiro para trabalhar o conbecimento do próprio corpo, e segundo esta questão cultural. [...] O papel da escola é mostrar esta questão que vai além da ciência, esta questão cultural. [Autor 2]

Este autor é de descendência nordestina e reside, no momento, em local diferente de sua cidade natal, onde ainda está em processo de adaptação. Talvez por vivenciar diferentes culturas dentro do Brasil, a questão cultural na EAN é relevante para o autor e tem sido refletida no LD de sua autoria com representações de alimentos de diferentes regiões do país.

Estes profissionais baseiam-se, também, na tradição de conteúdos veiculados em LD para gerenciar o conteúdo de cada série escolar nas páginas do LD. Não obstante, são as determinações do Edital do PNLD que mais cuidadosamente são analisadas e seguidas pelos autores, visto que é o objetivo dos produtores do LD que este seja comprado pelo MEC.

Conforme discutido anteriormente, as orientações do PNLD propiciam espaço para uma EAN abrangente; todavia, vale notar que as recomendações do PNLD 2014 aqui pontuadas abrangem todos os conteúdos de ciências do Ensino Fundamental II. Assim, muito embora a abordagem pedagógica adequada à EAN seja preconizada no Edital, uma determinada coleção pode atender estas orientações dentro de outros temas do ensino de ciências, que não a EAN.

A decisão de como apresentar os conteúdos é, sobretudo, do autor; não obstante, este entra em diálogo com a equipe editorial, que trabalha na multiplicidade de fatores envolvidos no processo de editoração, incluindo o número de páginas de cada obra. Cabe aos professores escolherem quais coleções deverão ser compradas pelo MEC, por conseguinte, o autor ocupase em considerar as abordagens pedagógicas mais favoráveis ao professor da escola pública brasileira. Um dos autores expressa esta situação.

As pessoas pensam que o LD determina o professor, mas é o contrário, é o professor que determina o livro didático [...] Este é um produto de mercado que precisa ser vendido. Uma grande parcela do que é o LD é o reflexo do que é o professor no Brasil, porque a gente faz.para vender. [...] As pessoas falam que o LD é muito tradicional, o LD é tradicional porque os professores são tradicionais. [Autor 2]

O espaço dedicado a um tema no LD refere-se tanto ao espaço físico tomado em suas páginas com atividades, textos e gravuras, quanto ao tempo despendido com a atividade dentro da hora aula. Consciente da limitação de carga horária dedicada a ciências no EFII, o autor, por vezes, abstém-se de sugerir um número elevado de exercícios que envolvam diálogos ou atividades práticas (como visitas a supermercados, por exemplo), embora estas sejam as mais adequadas à EAN. Além disso, o número de páginas que a editora designa para cada volume é um fator limitante:

Eu fiz mestrado em ciências de alimento, e sou bióloga, então eu faria um livro só sobre alimentação. Mas temos um limitador que é a quantidade de páginas. Temos que encaixar um conteúdo grande em um tempo curto e uma quantidade de páginas pequenas. A tarefa não é tão simples. [Autor 2] 
Em suma, ao autor, cabe grande parte das decisões referentes ao texto do livro didático. Estas, tanto em relação ao conteúdo quanto à abordagem pedagógica, passam por sua formação, história de vida e o crivo editorial. No entanto, os fatores de maior peso são as orientações do PNLD e as preferências do professor da escola pública brasileira, visto que o LD é mercadoria e o governo brasileiro é o maior comprador.

Diante disto, a total ausência de referências à merenda nas falas dos autores é intrigante, visto que merenda escolar é um programa governamental presente na escola. Esta lacuna persiste nos capítulos estudados dos LDs analisados. As hortas escolares, facilitadas pelo Projeto Educando com a Horta Escolar, parceria do FNDE com FAO/ONU (FUNDO NACIONAL DE DESENVOLVIMENTO DA EDUCAÇÃO, 2012), é mencionada pelo Autor 2 como excelente caminho para a EAN, todavia, a horta não encontra lugar nos textos analisados.

\section{O cotidiano da escola e a educação alimentar e nutricional no livro didático}

Garantir a presença da EAN no LD, de forma ampla e problematizadora, não é um fim em si. É essencial que o professor assimile esta compreensão e desenvolva atividades afins com seus alunos. Fatores diversos interferem neste processo.

Analisando a produção científica sobre educação em saúde, Harrison (2005) identifica que estas raramente estão presentes na literatura do ensino de ciências, mas, sim, na área da saúde. Uma possível explicação para esta realidade, cogita a autora, é que a identidade profissional do professor de ciências não abraça o rótulo de educador em saúde. Complementando estes pensamentos, McCaughtry et al. (2012) listam motivos que levam o professor a não desenvolver EAN, entre eles está a ausência de formação específica na área e em políticas públicas voltadas à alimentação. Além disto, estes autores argumentam que a EAN não goza status de disciplina essencial, podendo ser este um fato prejudicial ao seu desenvolvimento.

Ademais, a própria cultura de relacionamentos e interações em sala de aula interfere neste processo. Em conversa com um professor a respeito de uma atividade no LD 2 que favorece o diálogo, dificuldades no processo se tornaram evidentes:

Esta atividade do rótulo demora bastante tempo, porque todos têm que traz̧er o rótulo, ai 10 tražem e 20 não, então fica pra próxima aula. [...] É complicado, porque às vezes a gente pensa que é super simples, é só trazer o rótulo, mas eles não querem trazer as coisas, eles não gostam. É isto que às vezes faz a gente ficar mais preso na teoria, porque a gente tem que ficar naquela insistência, e isto é muito chato. [CO Prof-1]

Ao ser questionada em relação a outra atividade que sugere que o aluno entreviste uma pessoa que tenha tido problemas com excesso de colesterol, esta professora responde:

Acabamos não entrevistando. Eles [alunos], parece que vêem um empecilho nisto, nesta atividade de entrevista. É interessante. A atividade é viável, mas se eu deixar selecionada eles falam: Ah, professora, eu não fizporque tinha que entrevistar alguém... [...] Então, às vezes, eu falo que nem precisa fazer, porque eles acabam não fazendo, e como é que eu posso discutir uma coisa que não foi feita? [CO Prof-1] 
Espaços e caminhos da educação alimentar e nutricional ...

Além dos percalços explorados por CO Prof-1, é interessante notar que, embora as atividades descritas acima ofereçam escopo para uma abordagem problematizadora e próxima da realidade dos alunos, estas destoam das mais recentes orientações governamentais sobre o tema. $\mathrm{Na}$ atividade do rótulo, não há questionamento em relação ao consumo de produtos industrializados, contrastando com orientação para que se limite o uso de produtos prontos para o consumo encontrado no Novo Guia Alimentar. Ao abordar o colesterol, o tom ainda traduz uma conexão direta da EAN com a prevenção de doenças, diferente das orientações do Guia que, em vez de focarem em doenças, recomendam a seus leitores desenvolverem, exercitarem e partilharem habilidades culinárias (BRASIL, 2014b).

Mesmo quando não fornecem somente atividades de cunho estritamente biológico, muitas das atividades propostas nos LDs analisados não se aprofundam nas questões imbricadas na EAN. Trazemos, aqui, um exemplo do Livro 3, que consiste em uma pergunta isolada em caixa de texto, no capítulo sobre alimentação e sistema digestório: "Você come frutas e verduras? "

Esta pergunta encontra-se ao lado de um pequeno texto intitulado "Eliminação", onde é trazida a importância das fibras para o bom funcionamento do intestino, acrescentando que frutas e verduras são alimentos ricos em fibras. A Professora NE Prof-1, em entrevista, disse que os alunos nem olham para este tipo de caixa de texto. Sem um maior encorajamento por parte do autor no Suplemento do Professor, também ausente neste caso, ou uma educação continuada ao professor, este tipo de atividade pode não resultar em um processo educacional efetivo em alimentação e nutrição.

Contrastando com os achados nas entrevistas com os autores e análise dos $\mathrm{LD}$, a questão da merenda e das hortas escolares brotaram como ponto natural de discussão nos discursos dos professores. Relembramos que o PNAE tem a EAN como um dos seus objetivos na oferta da merenda escolar. Da mesma forma, o Projeto Educando com a Horta Escolar (PEHE) busca a criação de hábitos alimentares saudáveis e a promoção da conscientização ambiental ao usar a horta escolar como espaço pedagógico prazeroso e lúdico (FUNDO NACIONAL DE DESENVOLVIMENTO DA EDUCAÇÃO, 2012).

\section{Identificando caminhos para a otimização da educação alimentar e nutricional no livro didático}

Os espaços onde o LD é produzido e utilizado são claros: instâncias governamentais, editoras e escola pública. Cada um desses espaços, potencialmente, traz sua contribuição para que o aluno da escola pública receba educação alimentar e nutricional. Buscar-se-á, nas próximas linhas, discorrer sobre possíveis caminhos que favoreçam o diálogo e a interação entre os espaços acima citados para uma otimização da EAN oferecida pelo LD.

Voltando o olhar para os espaços governamentais, entende-se que deva haver uma interação entre programas que tenham tanto EAN em seus objetivos quanto o aluno de escola pública como público-alvo. Além do PNLD, o PNAE, o PEHE já citados, o Programa Saúde na Escola prevê a educação permanente em saúde, da qual faz parte a EAN. Em pesquisa sobre PSE, Casemiro (2013) revela que, no contexto estudado, havia pouco conhecimento sobre as ações do PSE e do PNAE entre os profissionais que atuavam na área, e aponta caminhos oportunos para a EAN no contexto do PSE que passam por um diálogo mais consistente entre este programa e o PNAE. 
Oferecendo questionamentos que instiguem discussão sobre a merenda, a horta escolar ou atividades desenvolvidas pelo PSE, o LD pode facilitar e fortalecer o processo educativo em alimentação e nutrição intencionado por cada um destes programas dentro da escola local. A cotidianidade da merenda escolar, por exemplo, naturalmente resulta em diálogos entre aqueles que dela se beneficiam, ou seja, alunos e, por vezes, professores. Todavia, esses diálogos não têm, necessariamente, uma intencionalidade educativa, esvaziando, assim, oportunidades valiosas para um processo educativo baseado na realidade concreta. $\mathrm{O}$ texto e as atividades propostas pelo LD podem oferecer o gatilho que injetaria intencionalidade a estas discussões, enriquecendo esta ação educativa.

No entanto, para que isto ocorra, faz-se necessário envolver a campo editorial, para que o autor do livro didático escolha oferecer uma conexão com estes programas, a saber, PNAE, PEHE e PSE, ao desenvolver EAN no LD. Diante da multiplicidade de temas que devem estar presentes no LD e o fato de que o autor não necessariamente tenha EAN como uma de suas especialidades, faz-se necessário, primeiramente, engajá-lo nesta linha de pensamento. Um caminho até o autor é o próprio PNLD, por meio do seu Edital e processo de avaliação. Nestas duas instâncias, o governo comunica-se com um público de autores ávidos para atenderem as demandas governamentais e incorporá-las nos livros de sua autoria.

O Marco pode pavimentar um segundo caminho até o autor. Neste documento do Ministério do Desenvolvimento Social e Combate à Fome (MDS), encontra-se o planejamento para investimento na formação de profissionais envolvidos nas diferentes áreas do conhecimento e promoção de processos de educação permanente, considerando as diferentes necessidades dos profissionais. Dado o grande potencial de influência do autor do LD, é essencial atrair este profissional para os espaços de reflexão e orientação prática promovidos pelo Marco, afinando este profissional com os avanços conceituais em EAN, incluindo a presença desta no PNAE, PSE e PEHE. Para fortalecer o potencial da EAN no LD, avaliadores do livro de ciências do PNLD também devem estar nestes espaços de reflexão e diálogo promovidos pelo MDS.

$\mathrm{Na}$ realidade, o LD é um instrumento ímpar para o cumprimento dos propósitos e objetivos do Marco, que tem, como estratégia, a viabilização da presença da EAN no currículo das escolas.

Todavia, assegurar-se da presença de EAN no LD, abordada de forma problematizadora e conectada com a realidade, não é suficiente. Ainda se faz necessário que o professor se sinta encorajado e capaz de desenvolver estas atividades. A educação permanente de professores contemplada no Marco, tanto por parte das Secretarias de Educação locais quanto por meio dos Centros Colaboradores em Alimentação e Nutrição do Escolar (CECANE), torna-se essencial neste processo educativo.

Vale aqui considerar que o texto do LD utilizado na escola privada é, essencialmente, o mesmo da escola pública, mas os programas governamentais mencionados não contemplam a primeira. Não obstante, alimentos são consumidos em todos os espaços escolares e hortas marcam presença, também, em escolas privadas. Assim, ao abordarem o alimento que se come 
na escola, autores podem expressar-se de maneira relevante aos dois contextos. Quanto à horta escolar, parece não haver diferença significativa no vocabulário das duas realidades. O PSE, por sua vez, não apresenta um equivalente na escola privada, todavia, o suplemento do professor dos livros do PNLD pode ser utilizado para incentivar trabalho conjunto do PSE com a EAN desenvolvida pelo professor da escola pública.

\section{Conclusão}

A EAN é valorizada na promoção da saúde e tem sido objetivo comum de programas governamentais que contemplam o escolar. O LD de ciências, disponibilizado a todo aluno da escola pública brasileira, apresenta-se como ferramenta importante para o desenvolvimento da EAN.

Em seu processo de produção, o LD é fortemente influenciado pelas diretrizes governamentais e pela preferência dos professores. Não obstante, encontram-se no campo editorial, sobretudo na figura do autor, as decisões sobre a escrita do texto e a formatação do produto final. Dentro do contexto escolar, cabe ao professor o poder de decisão em relação à maneira como o conteúdo do LD é utilizado.

Tendo em vista a natureza da EAN, entendemos que o mediador, neste processo educativo, deve ser o alimento relevante e acessível aos atores sociais envolvidos. Ademais, visualizamos a necessidade de uma interação mais ampla entre os programas governamentais que têm a EAN entre os seus objetivos e o aluno de escola pública como público-alvo. A merenda escolar, da mesma forma que o LD, é disponibilizada pelo governo a todos os estudantes da escola pública. Apesar de a EAN estar entre seus objetivos, não foi encontrado este vínculo nos textos dos livros didáticos pesquisados, desperdiçando uma oportunidade de fortalecimento deste processo educativo. Da mesma forma, o PHEH e o PSE poderiam ser potencializados junto ao PNLD na busca da efetividade da EAN.

O Marco de Referência de Educação Alimentar e Nutricional para as Políticas Públicas (BRASIL, 2012), ao lado de outras discussões deste campo, promovem espaços de reflexão e orientação prática que poderão auxiliar na coordenação das ações de EAN no ambiente escolar, seja ele privado ou público. Autores de livros didáticos e professores de ciências teriam muito a ganhar e, também, a contribuir nestes processos de discussão da EAN, que certamente encontra, na escola, um espaço central para sua prática. Cabe aos profissionais envolvidos nesta temática identificarem quais caminhos podem ser construídos conjuntamente para o fortalecimento do processo educativo e das ações de saúde relacionadas à alimentação.

Acreditamos que, neste processo, a merenda e a horta escolar encontrarão espaço no LD.

Da mesma forma, o envolvimento do professor de ciências nos espaços de formação e reflexão promovidos pelo Marco pode trazer o entusiasmo e conhecimento técnico necessário ao fortalecimento do processo educativo em alimentação e nutrição sugerido pelo LD. 
Greenwood, S. A.; Fonseca, A. B.

\section{Referências}

AMPARO-SANTOS, L. Avanços e desdobramentos do marco de referência da educação alimentar e nutricional para políticas públicas no âmbito da universidade e para os aspectos culturais da alimentação. Revista de Nutrição, Campinas, v. 26, n. 5, p. 595-600, 2013. Disponível em: <http://dx.doi.org/10.1590/S1415-52732013000500010>. Acesso em: 11 mar. 2014.

BIZZO, M. L. G.; LEDER, L. Educação nutricional nos parâmetros curriculares nacionais para o ensino fundamental. Revista de Nutrição, Campinas, v. 18, n. 5, p. 661-667, 2005. Disponível em: <http://dx.doi.org/10.1590/S1415-52732005000500009>. Acesso em: 11 mar. 2014.

BOOG, M. C. F. Educação nutricional: passado, presente e futuro. Revista de Nutrição, Campinas, v. 10, n. 1, p. 5-19, 1997.

BOURDIEU, P.; PASSERON, J. C. A reprodução: elementos para uma teoria do sistema de ensino. Rio de Janeiro: Francisco Alves, 1975.

BRASIL. Constituição (1988). Constituição: República Federativa do Brasil. Brasília: Senado Federal, 1988.

Lei no 8.069, de 13 de julho de 1990. Dispõe sobre o Estatuto da Criança e do Adolescente e dá outras providências. Diário Oficial da União, Brasília, 16 jul. 1990a. Disponível em: <http://www.planalto.gov.br/ccivil_03/LEIS/L8069.htm>. Acesso em: 13 nov. 2015.

Lei n ${ }^{\circ}$ 8.080, de 19 de setembro de 1990. Dispõe sobre as condições para a promoção, proteção e recuperação da saúde, a organização e o funcionamento dos serviços correspondentes e dá outras providências. Diário Oficial da União, Brasília, 20 set. 1990b. Disponível em: <http://www.planalto.gov.br/ccivil_03/Leis/L8080.htm>. Acesso em: 13 nov. 2015.

Lei $\mathrm{n}^{\circ}$ 9.394, de 20 de dezembro de 1996. Estabelece as diretrizes e bases da educação nacional. Brasília, 1996. Disponível em: < http://portal.mec.gov.br/arquivos/pdf/ ldb.pdf>. Acesso em: 13 nov. 2015.

. Ministério da Educação. Edital de convocação 06/2011 - CGPLI: edital de convocação para o processo de inscrição e avaliação de coleções didáticas para o Programa Nacional do Livro Didático PNLD 2014. Brasília, 2011.

. Ministério da Educação. Guia PNLD 2013. Brasília, 2013.

. Ministério da Educação. Guia PNLD 2014. Brasília, 2014a. Disponível em: $<$ http:/ /www.fnde.gov.br/programas/livro-didatico/guias-do-pnld/item/4661-guiapnld-2014>. Acesso em: 13 nov. 2015.

Ministério da Educação. Parâmetros curriculares nacionais: apresentação dos temas transversais. Brasilia, 1997. 
Espaços e caminhos da educação alimentar e nutricional ...

BRASIL. Ministério da Saúde. Guia alimentar para a população brasileira. Brasília, 2014b. Disponível em: <http://www.foodpolitics.com/wp-content/uploads/BrazilsDietary-Guidelines_2014.pdf>. Acesso em: 13 nov. 2015.

- Ministério do Desenvolvimento Social e Combate à Fome. Marco de referência de educação alimentar e nutricional para as políticas públicas. Brasília, 2012. Disponível em: <http://www.mds.gov.br/webarquivos/publicacao/seguranca_alimentar/marco_EAN. pdf $>$. Acesso em: 13 nov. 2015.

CASEMIRO, J. P. Cultura, participação e educação popular \& saúde: a educação alimentar e nutricional como lugar de encontro na escola. 2013. 370 f. Tese (Doutorado em Educação em Ciências e Saúde) - Núcleo de Tecnologia Educacional para a Saúde, Universidade Federal do Rio de Janeiro, Rio de Janeiro, 2013.

FREIRE, P. Pedagogia da autonomia: saberes necessários à prática educativa. Rio de Janeiro: Paz e Terra, 1996.

FUNDO NACIONAL DE DESENVOLVIMENTO DA EDUCAÇÃO. Dados estatísticos PNLD. Brasília, 2014. Disponível em: <http://www.fnde.gov.br/programas/ livro-didatico/livro-didatico-dados-estatisticos>. Acesso em: 13 nov. 2015.

. Encontro nacional avalia projetos de hortas escolares. Sala de Imprensa, 21 ago.

2012. Disponível em: < http://www.fnde.gov.br/fnde/sala-de-imprensa/noticias/item/3731encontro-nacional-avalia-projetos-de-hortas-escolares>. Acesso em: 13 nov. 2015.

HARRISON, J. K. Science education and health education: locating the connections. Studies in Science Education, Abingdon, v. 41, n. 1, p. 51-90, 2005.

McCAUGHTRY, N. et al. Urban health educators' perspectives and practices regarding school nutrition education policies. Health Education Research, Cary, v. 27, n. 1, p. 69-80, 2012.

MEGID NETO, J.; FRACALANZA, H. O livro didático de ciências: problemas e soluções. Ciência \& Educação, Bauru, v. 9, n. 2, p. 147-157, 2003. Disponível em: <http://dx.doi. org/10.1590/S1516-73132003000200001>. Acesso em: 11 mar. 2014.

PIPITONE, M. A. P. et al. A educação nutricional no programa de ciências para o ensino fundamental. Saúde em Revista, Piracicaba, v. 5, n. 9, p. 29-37, 2003. Disponível em: $<$ http://www.unimep.br/phpg/editora/revistaspdf/saude09art04.pdf > . Acesso em: 17 nov. 2015.

ROSA, M. D. Seleção e uso do livro didático na visão de professores de ciências: um estudo na rede municipal de ensino de Florianópolis. 2013. Dissertação (Mestrado em Educação Científica e Tecnológica) - Universidade Federal de Santa Catarina, Florianópolis, 2013. Disponível em: <https://repositorio.ufsc.br/handle/123456789/107364>. Acesso em: 17 nov. 2015.

THOMPSON, J. B. Ideologia e cultura moderna: teoria social crítica na era dos meios de comunicação de massa. Petrópolis: Vozes, 1995. 
Greenwood, S. A.; Fonseca, A. B.

Artigo recebido em 13/03/2014. Aceito em 29/06/2015.

Endereço para contato:

Avenida Carlos Chagas Filho, 373, Bloco A, Sala 12, Centro de Ciências da Saúde, Cidade Universitária, CEP 21949-902, Rio de Janeiro, RJ, Brasil. 